\title{
Managing the Needs of Older Patients with Multimorbidity-A Systematic Review of the Challenges Faced by the Healthcare Services
}

\author{
Anne Lise Holm¹, Astrid Karin Berland', Elisabeth Severinsson ${ }^{2}$ \\ ${ }^{1}$ Department of Health Science, Stord/Haugesund University College, Stord, Norway \\ ${ }^{2}$ Centre for Women's, Family and Child Health, Faculty of Health Sciences, University College of Southeast Norway, Kongsberg, Norway \\ Email: anne.holm@hsh.no
}

How to cite this paper: Holm, A.L., Berland, A.K. and Severinsson, E. (2016) Managing the Needs of Older Patients with Multimorbidity-A Systematic Review of the Challenges Faced by the Healthcare Services. Open Journal of Nursing, 6, 881-901. http://dx.doi.org/10.4236/ojn.2016.610086

Received: September 21, 2016

Accepted: October 25, 2016

Published: October 28, 2016

Copyright $\odot 2016$ by authors and Scientific Research Publishing Inc. This work is licensed under the Creative Commons Attribution International License (CC BY 4.0).

http://creativecommons.org/licenses/by/4.0/

\begin{abstract}
Research fails to provide an overview of the challenges involved in caring for older patients with multimorbidity. Multimorbidity is defined as the presence of two or more chronic conditions in the same person, leading to a high risk of care dependency. The aim of this review was to illuminate the challenges faced by the healthcare services in managing the needs of older patients with multimorbidity. A systematic review was performed, a total of 1,965 abstracts were read and nine quantitative studies included. Data were analysed by thematic synthesis, revealing six themes: A frequent problem in older female patients; High healthcare expenditure and costs, Medication management problems, Social inequities, Complex healthcare and consultation needs and High mortality. The study highlights that healthcare professionals struggle to obtain suitable guidelines for the care of patients with multimorbidity while trying to respond to their needs. Patient-centred integration across settings and coordination in clinical practice are necessary. The healthcare system today does not seem to focus on patient safety and preventing harm. Older patients should be reviewed by a healthcare professional responsible for coordinating their care. To ensure safe and effective care for elderly persons with multimorbidity, the healthcare services should abandon the current focus on managing innumerable individual diseases and conditions.
\end{abstract}

\section{Keywords}

Healthcare Services, Multimorbidity, Older Patients, Systematic Review, Thematic Synthesis

\section{Introduction}

The healthcare needs of older patients with mutimorbidity are described as one of the 
challenges for healthcare systems across the world in the $21^{\text {st }}$ century [1]. However, research fails to provide an overview of the challenges involved in caring for older patients with multimorbidity. Multimorbidity is defined as the presence of two or more chronic conditions in the same person, leading to a high risk of care dependency [2]. In the last decade some studies have focused on the healthcare needs of older patients with multimorbidty. In nursing research, Summer Meranius and Engstrom [3] explored medication self-management among older people with multimorbidity. The participants experienced uncertainty that increased with their experience of side effects, leading to concern that the medication might be harmful. Four other qualitative studies investigated perceptions and experiences of older patients with multimorbidity, mainly from the perspective of physicians [4]-[7]. Bayliss et al. [4] revealed that the patients wanted easy access to healthcare, individualized care plans, support from one care coordinator and continuity of relationships with healthcare professionals who had a caring attitude, listened to them and appreciated that their needs were unique and fluctuating. Fortin et al. [5] demonstrated that patients with multimorbidity were open to the participation of nurses in primary care practice. They expected greater accessibility for both themselves and for other patients. Grundberg et al. [6] described the variation in how older persons with multimorbidity perceived their mental health and what influences it. Mental health was defined as how a person feels and included a positive as well as a negative aspect. Social contacts, physical activity and optimism may improve mental health, while social isolation, ageing and chronic pain may cause it to deteriorate [6]. Gustafsson et al. [7] found one theme; Challenging current professional identity based on three sub-themes; 1) Adjusting to familiar work in an unfamiliar role; 2) Striving to improve the health system through a new role; 3) Trust is vital for advocacy [7]. A cross-sectional study by Noël et al. [8] compared the self-management learning needs and willingness to encounter non-physician care providers of patients with multimorbidity and those with a single chronic illness. They concluded that the self-management learning needs of patients with multimorbidity are extensive and that they prefer team-based primary care [8].

According to Salisbury [9], the management of patients with multimorbidity is now the most important task facing health services in developed countries, which presents a fundamental challenge to the single-disease focus. The aging population means that the proportion of people with several coexisting health problems is increasing rapidly. Thus, while multimorbidity is not only a problem for older people, the prevalence is much higher in older age groups, with $65 \%$ of people aged $65-84$ years and $82 \%$ of people aged 85 years and over suffering from coexisting illnesses [10]. Older people with multimorbidity have a higher degree of disability, psychological distress, risk of mortality and utilization of healthcare services than if one considered one of their chronic conditions in isolation [11]. The relationship between different chronic diseases and conditions can increase risk factors referred to as patient complexity [12]. Older people need to maintain autonomy despite reduced health, for which they require social support and high quality healthcare services [12]. There is an urgent need to describe the characteristics of older people with multimorbidity, such as their demographic and 
cultural background, earlier crises and trauma at personal and/or social level [12] [13].

Healthcare systems and models need clinical guidelines related to self-management for older people [14]. According to Salisbury [9], healthcare professionals should focus more on learning how to promote patient self-management, including how different physical and mental health problems and diseases interact and how to help the patient to make healthcare decisions in the face of competing priorities. Older people with depression and physical diseases need self-management ability to prevent stigma and social exclusion [15]-[17].

Nursing research on older persons with multimorbidity from a health and home care perspective is lacking. Nursing care is essential in both home and primary care. In the healthcare services the involvement of different healthcare professionals can increase the risk of competing demands in treatment and care, resulting in reduced coordination and communication [17], as well as fragmentation of the healthcare system [18].

\section{Aim}

The aim of this study was to illuminate the challenges faced by the healthcare services in managing the needs of older patients with multimorbidity.

\section{Methods}

A systematic review method was used to investigate the quality of the included studies [19].

\subsection{Inclusion and Exclusion Criteria}

The studies, which were published between January 2005 and December 2015, included older adults aged 50 years and over. The inclusion criteria were: published in the English language in peer-reviewed journals, multimorbidity, house-bound elderly individuals, healthcare, home healthcare. The exclusion criteria were: review studies, qualitative studies, theoretical studies, studies of younger persons, studies published before 2005 and studies without multimorbidity, health, healthcare, health utilization or healthcare services in the title.

\subsection{Literature Search}

Electronic searches were performed in Academic Search Premier (290), Ovid Medline (1), PubMed (812), CINAHL (90) and ProQuest (772) for the period January 2005December 2015 (see Table 1). A total of 1965 abstracts were read and 30 studies retrieved for further investigation. A manual search yielded an additional two studies. The retrieval and selection process, which is presented in Figure 1, resulted in a total of nine quantitative studies.

\subsection{Evaluation of the Included Studies}

A systematic evaluation was conducted on the studies that met the inclusion criteria, which comprised an assessment of the validity and a systematic presentation of the 
findings. Similar evaluations have been done of in earlier systematic reviews [20] [21]. In this study the PRISMA checklist was employed [22], Table 2.

The studies included a broad spectrum of content, measurements and statistical analyses across varying time periods, making a meta-analysis impossible [23]. An important aspect of systematic reviews is examination of the methodologies of the primary studies [19] [21]. The PRISMA checklist was used to review methodological aspects of the design, sample size, response rate, causality, measurements, generalization and ethical approval [20], in addition to other methodological literature [19] [23]-[25].

Design; Five of the studies were described as having a cross-sectional design [26] [28]-[30]. One study took the form of a survey [31], while one was part of a longitudinal

Table 1. The search process in databases.

\begin{tabular}{ccc}
\hline Academic Search Premier & Search words & Results \\
\hline & multimorbidity, elderly & 219 \\
& AND healthcare & 57 \\
& AND/OR home healthcare, healthcare services & 14 \\
Ovid Medline & multimorbidity, elderly & 1 \\
PubMed & AND/OR home healthcare & 533 \\
& AND/OR healthcare services & 279 \\
CINAHL & multimorbidity, elderly & 89 \\
& AND/OR home healthcare, healthcare services & 1 \\
ProQuest & multimorbidity, elderly & 772
\end{tabular}

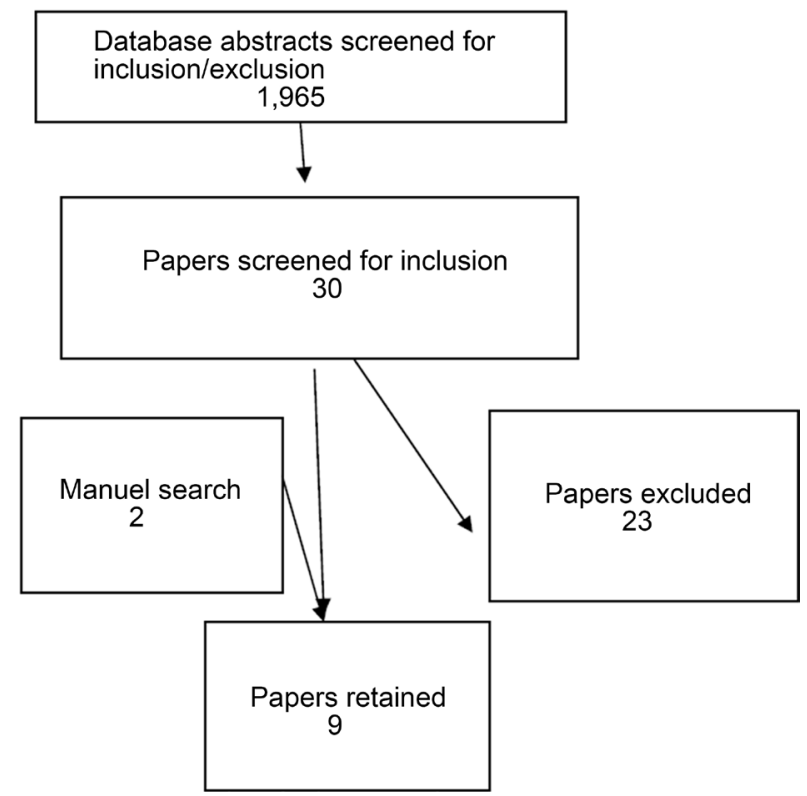

Figure 1. Search and retrieval process. 
Table 2. Summary of articles on the healthcare services and older patients with multimorbidity.

\begin{tabular}{|c|c|c|c|c|}
\hline $\begin{array}{l}\text { Author } \\
\text { Year, } \\
\text { Country }\end{array}$ & Aim & $\begin{array}{l}\text { Design } \\
\text { Measurements }\end{array}$ & $\begin{array}{l}\text { Statistical } \\
\text { Analysis }\end{array}$ & Conclusion \\
\hline $\begin{array}{l}\text { 1. Bähler et al. (2015) } \\
\text { SWITZERLAND }\end{array}$ & $\begin{array}{l}\text { To examine the association } \\
\text { between multi-morbidity, } \\
\text { healthcare utilization and } \\
\text { costs in the community. }\end{array}$ & $\begin{array}{l}\text { Quantitative, } \\
\text { cross-sectional. } \\
\text { PCG. }\end{array}$ & $\begin{array}{l}\text { Descriptive } \\
\text { statistics. }\end{array}$ & $\begin{array}{l}\text { The burden of multi-morbidity is a fundamental } \\
\text { aspect the management of patients in health } \\
\text { service delivery systems and for healthcare policy } \\
\text { debates about resource allocation. Strategies for } \\
\text { better coordination of multi-morbid patients are } \\
\text { urgently needed. }\end{array}$ \\
\hline $\begin{array}{l}\text { 2. Glynn et al. (2011) } \\
\text { IRELAND }\end{array}$ & $\begin{array}{l}\text { To examine the prevalence } \\
\text { and associated healthcare } \\
\text { utilization and cost of } \\
\text { patients with } \\
\text { multimorbidity. }\end{array}$ & $\begin{array}{l}\text { Quantitative } \\
\text { ICPC-2, HSU, HCC. }\end{array}$ & $\begin{array}{l}\text { Binary Logistic } \\
\text { regression. }\end{array}$ & $\begin{array}{l}\text { Multi-morbidity is common in primary care and } \\
\text { in a system with strong gate-keeping is associated } \\
\text { with high healthcare utilization and cost. } \\
\text { Interventions to address quality and cost } \\
\text { associated with multi-morbidity must focus on } \\
\text { primary as well as secondary care. }\end{array}$ \\
\hline $\begin{array}{l}\text { 3. Holzhausen et al. } \\
\text { (2011) } \\
\text { GERMANY }\end{array}$ & $\begin{array}{l}\text { To develop a conceptual } \\
\text { framework and a set of } \\
\text { standardized instruments } \\
\text { and indicators for } \\
\text { continuous monitoring of } \\
\text { multi-morbidity and } \\
\text { associated healthcare } \\
\text { needs in the population. }\end{array}$ & $\begin{array}{l}\text { Quantitative, } \\
\text { longitudinal. } \\
\text { ADL, BSSS, DSST, } \\
\text { CAPI, CATI, } \\
\text { IPANAS, OMAHA, } \\
\text { MILVA, PCI, PHQ, } \\
\text { SWLS, QoL, FLQM. } \\
\text { Self-administered } \\
\text { questionnaire. }\end{array}$ & Not reported. & $\begin{array}{l}\text { This study added methodological and } \\
\text { content-specific discourses on human resources } \\
\text { for maintaining quality of life and autonomy } \\
\text { throughout old age, even in the face of multiple } \\
\text { health complaints. }\end{array}$ \\
\hline $\begin{array}{l}\text { 4. Jowsey et al. (2013) } \\
\text { AUSTRALIA }\end{array}$ & $\begin{array}{l}\text { To identify how much } \\
\text { time people with multiple } \\
\text { chronic conditions spend } \\
\text { managing their health that } \\
\text { will help policy makers } \\
\text { and health service } \\
\text { providers make decisions } \\
\text { about areas in which } \\
\text { patients need support. }\end{array}$ & $\begin{array}{l}\text { Quantitative, cross } \\
\text { sectional survey. } \\
\text { Recall questionnaire } \\
\text { COPD, NDSS, NSA. }\end{array}$ & $\begin{array}{l}\text { Descriptive } \\
\text { analyses. }\end{array}$ & $\begin{array}{l}\text { Multi-morbidity imposes considerable time } \\
\text { burdens on patients. Ageing is associated with } \\
\text { increasing rates of multi-morbidity. Many older } \\
\text { adults experience high demands on their time to } \\
\text { manage their health in the face of decreasing } \\
\text { energy and mobility. Their time use must be } \\
\text { considered in health service delivery and health } \\
\text { system reform. }\end{array}$ \\
\hline $\begin{array}{l}\text { 5. Nunes et al. (2015) } \\
\text { BRAZIL }\end{array}$ & $\begin{array}{l}\text { To verify the prevalence } \\
\text { and distribution of } \\
\text { multi-morbidity in } \\
\text { Brazilian older adults. }\end{array}$ & $\begin{array}{l}\text { Quantitative. } \\
\text { Cross-sectional. } \\
\text { Face-to-face } \\
\text { interviews. } \\
\text { Structured } \\
\text { self-reported } \\
\text { questionnaires. }\end{array}$ & Stat version 12 & $\begin{array}{l}\text { Multimorbidity frequency was high in the sample } \\
\text { studied. The social inequities identified increased } \\
\text { the challenges faced by the health system in the } \\
\text { management of multimorbidity, requiring } \\
\text { comprehensive and multidimensional care. The } \\
\text { combinations of diseases can provide an initial } \\
\text { reason for including multimorbidity in Brazilian } \\
\text { clinical protocols. }\end{array}$ \\
\hline $\begin{array}{l}\text { 6. Orueta et al. (2014) } \\
\text { USA }\end{array}$ & $\begin{array}{l}\text { To present an overview of } \\
\text { the prevalence and costs of } \\
\text { multi-morbidity by } \\
\text { socio-economic levels in } \\
\text { the whole Basque } \\
\text { population. }\end{array}$ & $\begin{array}{l}\text { Quantitative } \\
\text { cross-sectional. }\end{array}$ & $\begin{array}{l}\text { Descriptive } \\
\text { statistics. }\end{array}$ & $\begin{array}{l}\text { Multi-morbidity is common and its prevalence } \\
\text { increases with age and an unfavorable } \\
\text { socio-economic environment. The costs of care } \\
\text { for patients with several chronic conditions } \\
\text { cannot be described as the average sum of their } \\
\text { individual pathologies. Given the ageing } \\
\text { population, multi-morbidity and its consequences } \\
\text { should be taken into account in healthcare policy, } \\
\text { the organization of care and medical research. }\end{array}$ \\
\hline $\begin{array}{l}\text { 7. Perruccio et al. } \\
\text { (2012) } \\
\text { CANADA }\end{array}$ & $\begin{array}{l}\text { To investigate the } \\
\text { association between } \\
\text { multi-morbidity-a } \\
\text { construct comprising } \\
\text { several health } \\
\text { domains-and overall } \\
\text { self-rated health (SRH), an } \\
\text { important chronic disease } \\
\text { health outcome. }\end{array}$ & $\begin{array}{l}\text { Quantitative survey. } \\
\text { SRH. }\end{array}$ & $\begin{array}{l}\text { Bivariate } \\
\text { analyses. }\end{array}$ & $\begin{array}{l}\text { The findings suggested that focus on one domain } \\
\text { in health research may limit the researchers' } \\
\text { ability to understand health outcomes for which } \\
\text { SRH is a predictor. }\end{array}$ \\
\hline
\end{tabular}




\begin{tabular}{|c|c|c|c|c|}
\hline $\begin{array}{l}\text { 8. Tooth et al. (2008) } \\
\text { AUSTRALIA }\end{array}$ & $\begin{array}{l}\text { To develop indexes of } \\
\text { multi-morbidity based on } \\
\text { self-reported data, to } \\
\text { predict mortality, health } \\
\text { service use, help with } \\
\text { activities of daily living } \\
\text { (ADL) and health-related } \\
\text { quality of life (HRQOL) in } \\
\text { older women. }\end{array}$ & $\begin{array}{l}\text { Quantitative, } \\
\text { cross-sectional } \\
\text { survey. } \\
\text { Self-reported } \\
\text { questionnaires. } \\
\text { ADL, HRQOL. }\end{array}$ & $\begin{array}{l}\text { Multiple linear } \\
\text { regression. }\end{array}$ & $\begin{array}{l}\text { These multi-morbidity indexes predict mortality, } \\
\text { health service use, help with ADL and HRQOL in } \\
\text { older women. The indexes could be used as } \\
\text { covariates in research, with weighted scores } \\
\text { having a better chance of discriminating between } \\
\text { patient groups than unweighted scores. }\end{array}$ \\
\hline $\begin{array}{l}\text { 9. Van Oostrom et al. } \\
\text { (2014) THE } \\
\text { NETHERLANDS }\end{array}$ & $\begin{array}{l}\text { To examine the } \\
\text { relationship between } \\
\text { having multiple diseases } \\
\text { and the number of } \\
\text { contacts with general } \\
\text { practice. }\end{array}$ & $\begin{array}{l}\text { Quantitative } \\
\text { LINH. }\end{array}$ & $\begin{array}{l}\text { Negative } \\
\text { binomial } \\
\text { regression } \\
\text { analyses with a } \\
\text { log-link } \\
\text { function. }\end{array}$ & $\begin{array}{l}\text { Multi-morbidity is associated with increased } \\
\text { healthcare utilization in general practice, yet the } \\
\text { increase declines per additional disease. } \\
\text { Nevertheless, with the expected rise in } \\
\text { multi-morbidity in the coming decades more } \\
\text { extensive health resources will be required. }\end{array}$ \\
\hline
\end{tabular}

ADL, Activities of Daily Living. B.IPQ, Brief Illnes Perceptions Questionnaire. BSSS, Assessment of subjective social support. CAPI, CATI, Computer Assisted Interviews. Nationwide population sample of men and women aged 65 years and older who participated in previous German Health Telephone Surveys. DSST, Digit Symbol Substitution Test. FLQM, Fragebogen zur Lebensqualität multimorbider älterer Menschen. HSRQOL, Health Related Quality of Life. ICPC, International Classification of Primary Care. HSU, Health Services Utilization. HCC, Health Care Costs. IPANAS, International Positive and Negative Affect Schedule. LINH, the Netherlands Information Network of General Practice. NDSS, National Diabetes Services Scheme. NSA, National Seniors Australia. PCG, Pharmacy-based Cost Group. OMAHA, population-based longitudinal epidemiological study of multimorbidity in population aged 65 years and older. PACIC, Patient Assessment of Chronic Illness Care. PCI, Proactive Coping Inventory. PHQ, Patient Health Questionnaire. SRH, Self-Rated Health.

design [30]. There was no information about the design in two of the studies [33] [34]. Causality; It was stated in one cross-sectional study that the design made it impossible to draw any causal conclusions [29]. Four of the other cross-sectional studies did not discuss any problems related to causality or internal validity [26] [28] [30]. Holzhausen et al. [32] reported that their longitudinal study provided opportunities for analyses of health trajectories, longitudinal relationships of outcome determinants and most importantly, causal relationships between conditions and trajectories over an 18 month period. Perrucio et al. [31] stated that their survey intended to convey theorized causal pathways and not longitudinal evolution. Selection bias, It was reported in one study that the findings could be subject to selection bias [29]. Nunes et al. [30] stated that the probability of selection bias in their population-based study was low due to the small number of drop outs and refusals [30]. Holzhausen et al. [32] recommended that a strategy of oversampling underrepresented, yet notably prevalent and politically important groups, could serve as a means of minimizing selection bias in future studies [32]. In one study it was suggested that the low response rate might have introduced selection bias because responders could have been more health conscious and hence more likely to report better self-rated health [31]. Three studies provided no information about selection bias [26] [28] [34]. However, Tooth et al. [26] stated that their sample was randomly selected with purposive oversampling in rural and remote areas [26]. The sample size of the studies ranged from $\mathrm{N}=9958$ to $\mathrm{N}=229,493$ (Table 2). In two studies the sample was described as relatively small [27] [33]. Four studies presented no information about selection bias related to sample size [26] [28] [31] [34]. Measurements, In one study it was stated that no standardized measure of multimorbidity exists for epidemiological surveys [29]. Different countries and research groups 
employ a variety of coding systems for chronic diseases, which means that results cannot be directly compared between countries [29]. One study reported the lack of a validated instrument for administration and that the assessment of subjective social support was restricted to one cohort [32]. Holzhausen et al. [32] stated that after completion of the analyses related to the validity and reliability of adaptations of existing measurement tools and a newly developed quality of life assessment, they would be able to provide a comprehensive set of instruments for face-to-face and telephone assessment in population-based health surveys. Seven studies provided no description of the validity or reliability of the measurements used [26]-[29] [31] [33] [34]. One study reported a limitation due to self-reported data [26]. Statistical analysis; Seven studies contained information about the statistical analysis used (Table 2), while two did not [30] [32]. Holzhausen et al. [32] explained that no power calculation was considered and that a statistician supervised, validated and, where necessary, corrected the data throughout the data collection process. Nunes et al. [30] described using Stata version 12. Generalization; In one study it was stated that generalizability was limited to elderly community dwelling individuals [31]. Another study used definitions to enhance the precision and generalizability of findings [33]. Three studies had samples that were predominantly female [26] [30] [31]. Seven studies did not mention anything about generalization to other older persons [26]-[30] [32] [34].

Demographic data; All the included studies contained some demographic data (see Table 3).

\subsection{Data Analysis}

The authors of the present review investigated the healthcare received by older patients with multimorbidity using a qualitative analysis to produce a thematic synthesis. The first author identified, grouped and summarized the findings as described by Pope et al. [35]. The thematic synthesis emerged by reading and re-reading the studies in order to synthesize the findings [19] [36]. Different patterns and concepts were identified across the data, leading to common meanings and concepts that were considered descriptions of the healthcare received by older patients with multimorbidity. The three authors discussed the emerging themes on several occasions before reaching consensus on the labelling.

\section{Findings}

The six themes pertaining to the needs of older patients with multimorbidity in the healthcare services were: A frequent problem in older female patients; High healthcare expenditure and costs, Medication management problems, Social inequities, Complex healthcare and consultation needs and High mortality (see Table 4).

\subsection{A Frequent Problem in Older Female Patients}

Six studies stated that multimorbidity was high and constituted a significant problem in older adults [28]-[32] [34]. Orueta et al. [28] added that the distribution of the population 
by age group, as well as the average number of chronic diseases per patient, was 0.97 overall. Multimorbidity affected more than half of the population over 65 years and more than three quarters of those aged between 80 and 84 years [28].

Table 3. Multimorbidity and demographic characteristics.

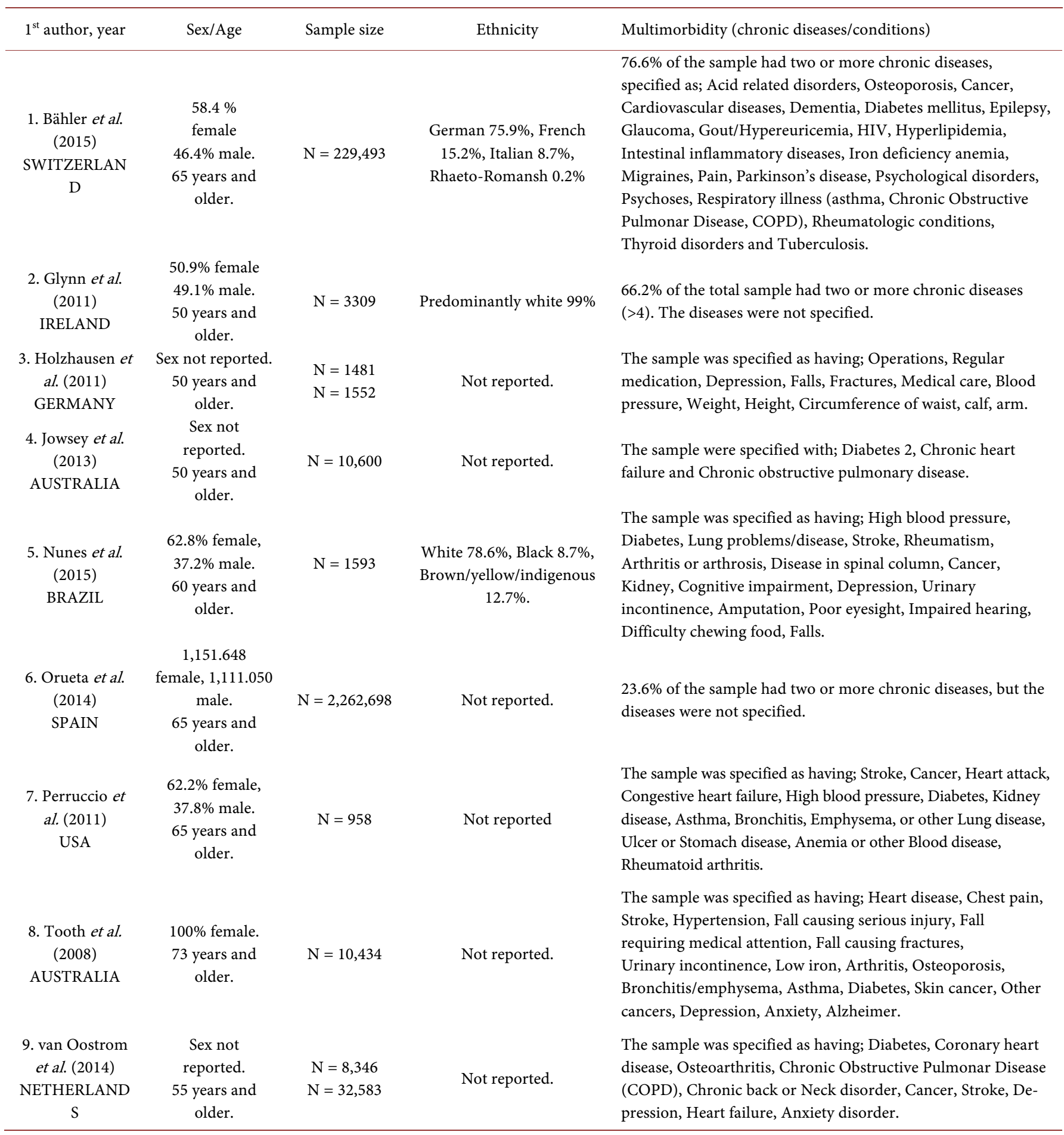

Cancer Surveillance Program (CSP); Breast Cancer Treatment Fund (BCTF); Self Reported Health (SRH). 
Table 4. Themes that emerged of the included studies.

\begin{tabular}{|c|c|c|c|c|c|}
\hline $\begin{array}{l}\text { A frequent } \\
\text { problem in } \\
\text { older female } \\
\text { patients }\end{array}$ & $\begin{array}{l}\text { High healthcare } \\
\text { expenditure and costs }\end{array}$ & $\begin{array}{l}\text { Medication } \\
\text { management } \\
\text { problems }\end{array}$ & Social inequities & $\begin{array}{l}\text { Complex healthcare and } \\
\text { consultation } \\
\text { needs }\end{array}$ & High Mortality \\
\hline $\begin{array}{l}\text { Worse } \\
\text { self-rated } \\
\text { health [31] } \\
{[32] .}\end{array}$ & $\begin{array}{l}\text { Increasing costs in } \\
\text { women aged } 75 \text { years } \\
\text { and older [29]. }\end{array}$ & $\begin{array}{l}\text { High number of } \\
\text { prescriptions } \\
{[34] \text {. }}\end{array}$ & $\begin{array}{l}\text { Low purchasing power } \\
\text { of a community } \\
\text { decreasing in } \\
\text { consultations [29]. }\end{array}$ & $\begin{array}{l}\text { More face-to-face and, } \\
\text { telephone consultations, home } \\
\text { visits, prescribing medications } \\
\text { [34]. } \\
\text { Over five times more hospitalized } \\
\text { [29]. }\end{array}$ & \\
\hline
\end{tabular}

Four studies revealed that multimorbidity was higher in women than in men [28]-[31]. Perruccio et al. [31] found that increasing age and female sex were associated with worse self-rated health. In contrast, Glynn et al. [33] revealed that gender had no significant effect.

Nunes et al. [30] stated that the higher frequency among women may be attributed to survival bias as men tend to die earlier and those who survive are usually the healthiest.

\subsection{High Healthcare Expenditure and Costs}

Three studies reported that patients with multimorbidity have high healthcare expenditure and costs [28] [29] [33].

Orueta et al. [28] stated that multimorbidity was responsible for $80.57 \%$ of total healthcare expenditure. $23.61 \%$ of patients with multimorbidity accounted for $63.55 \%$ of total healthcare expenditure. The total healthcare cost per person was higher in more socially deprived areas. The same trend was seen in patients with multimorbidity. These differences were statistically significant in all health expenditure categories, both for the general population and for patients with multimorbidity. For patients with 10 or more chronic diseases, the only statistically significant difference was expenditure on medications [28]. Orueta et al. [28] found it was not only the number of chronic diseases that matter when investigating the increased cost, but which chronic diseases the patients suffered from and especially what was considered to be their primary disease. Chronic obstructive pulmonary disease, diabetes mellitus, heart disease and heart failure increased the cost in line with the number of other coexisting diseases. Orueta et al. [28] demonstrated that on average, the use of healthcare resources by patients with multimorbidity grew with the number of chronic diseases. This increase was not linear but tended to be progressive, which was the most common pattern in such patients. Exceptions were depression and anxiety, as patients with either of these conditions and with more than two other chronic diseases used less resource than if they only had the other chronic health problems [28].

Bähler et al. [29] stated that outpatient services accounted for $50.8 \%$ of the total costs, 
inpatient services for $24.1 \%$ and medication for $25.1 \%$. The mean total healthcare costs were 5.5 times higher in patients with multimorbidity compared to those with no or only one chronic condition. There were considerably higher mean costs for patients with multimorbidity in both the inpatient and outpatient subgroups. The total healthcare cost per year was related to nursing dependency and total health care cost in the preceding year, followed by the number of chronic conditions. Costs increased by $32.6 \%$ for each additional chronic condition and almost doubled in patients who required home care nursing services [29]. In the analysis by Bähler et al. [29], the mean total costs were 5.5 times higher in the multimorbid compared to the non-multimorbid sample. The high standard deviations are consistent with the standard deviations in the cited articles, suggesting great variance and heterogeneity in the sample. Gender differences were found in health expenditure and costs, where costs were consistently higher in men aged 70 years or older, whereas in women costs decreased with increasing age [29]. A comparison between age and gender revealed that total costs increased by $9.10 \%$ in men aged 70 to 84 years compared to men aged $65-69$ years [29]. A slight increase of 5.7\% was found for the oldest age group. Overall, female gender was associated with lower costs, whereby costs decreased with increasing age for women aged 75 years and older [29]. The lowest total health care costs were therefore found in women aged 85 years and older, which represented a decrease of $12.1 \%$ compared to women in the youngest age group [29].

Glynn et al. [33] added that primary and secondary care was influenced by the need for multiple healthcare professionals. The impact of gatekeeping on healthcare utilization merits further consideration. According to Glynn et al. [33], there is a need to focus on coordinating the patient's journey through the healthcare system, while at the same time promoting "self-management" among patients with multimorbidity. Pairwise comparisons showed that the mean total cost increased significantly for patients with a number of chronic conditions compared to those with no chronic conditions [33].

\subsection{Medication Management Problems}

Two studies focused on medication management problems in patients with multimorbidity [27] [34]. Jowsey et al. [27] revealed that an alternative view of healthcare complexity was medication management. The patterns in the targeted samples were broadly in the expected direction, with the unexpected values pertaining to those in the small sample categories. There was a strong relationship between medications and reported time use [27]. The one really clear statistically significant item was the number of conditions related to time use in all sub-samples. Illness management was time consuming for patients with multimorbidity [27]. Van Ooström et al. [34] demonstrated that patients with multimorbidity had a higher number of prescriptions and more referrals to specialized care than those with one or no chronic disease.

\subsection{Social Inequities}

Two studies highlighted the social inequities in the health and care services [29] [30]. 
Bähler et al. [29] found a small but significant socio-economic gradient: the lower the purchasing power of a community, the lower the number of consultations. The decrease was $7.8 \%$ in patients living in a community with the lowest compared to the highest purchasing power. The lower the purchasing power of a community, the lower the costs per patient: the decrease was $3.4 \%, 6.6 \%, 9.5 \%$ and $13.4 \%$ with each reduction in the purchasing power quintile, compared to patients living in a community with the highest purchasing power [29]. Compared with the German-speaking part, the Italian-speaking part of Switzerland was associated with slightly lower costs of $2.3 \%$. No significant differences in the French and the Romansh speaking parts were found [29]. Choosing a higher deductible was significantly and negatively associated with total costs, amounting to a decrease of almost one fifth, where no association was found between the total costs and being in a managed care model [29]. Nunes et al. [30] confirmed the impact of social inequities as the elderly participants in their study were poor, less well educated and had no private health plan. While acknowledging that these factors might have been confused with socio-economic indicators, Nunes et al. [30] were of the opinion that an adjusted analysis would not make sense in view of the aims of their study and the fact that their sample had more diseases and greater social and financial vulnerability. Thus, health interventions related to the treatment and monitoring of chronic conditions should prioritize these individuals [30]. The occurrence of multimorbidity was higher among those with black or brown/yellow/indigenous skin, those with less education, less purchasing power, those who are bedridden, those who did not have an individual health plan, those who had medical consultations and visited emergency services, those who had been hospitalized and those living in community care [30] areas.

\subsection{Complex Healthcare and Consultation Needs}

Four studies revealed a trend of complex healthcare and/or consultation needs in patients with multimorbidity [29] [30] [33] [34]. Bähler et al. [29] reported that complex home nursing services and being in a managed care model were significantly associated with a higher number of consultations, an increase of $11.5 \%$ and $2.9 \%$ respectively. Living in the French or Italian speaking parts of Switzerland was associated with a lower number of consultations [29]. The effect of age on the increase in the number of consultations was greater in females compared to males. However, the number of consultations increased with advancing age in men, but the increase was less in women, although the results did not differ significantly for the last age group (women aged 84 to 89 years compared to 65 - 69 years). Women aged 85 years or older exhibited a significant decrease of $5.1 \%$ in the number of consultations, whereas an increase of $7.6 \%$ was found in men of the same age. $98.5 \%$ of patients with multimorbidity had at least one consultation in 2013 compared with $68.7 \%$ of patients without multimorbidity [29]. The sample of patients with multimorbidity was almost twice as likely to have had a consultation with a primary care physician and with a specialist. Approximately $22 \%$ of the patients with multimorbidity were seen by more than one primary care physician 
and over $54 \%$ consulted more than one specialist over the same time period. Patients with multimorbidity were 5.6 times more likely to be hospitalized compared to the patients without several diseases [29]. The mean number of consultations per year amounted to 15.7 in the patients with multimorbidity compared to 4.4 in the patients without multimorbidity [29].

Nunes et al. [30] found that the number of individuals requesting healthcare was significantly higher in the multimorbid group compared to the non-multimorbid sample. The most prevalent dyads of morbidities were high blood pressure and spinal column diseases (23.6\%) and high blood pressure and heart problems (22.3\%) [30]. Four of the dyads did not have a frequency that was statistically higher than expected. In the triads, this only occurred with the $\mathrm{HBP} /$ spinal column disease/cognitive impairment triplet. In the dyads, the highest ratio between observed and expected frequency was found for rheumatism and spinal column disease [30].

More specifically, Glynn et al. [33] found a significant interaction between age and gender, where the effect of age on the increase in the mean number of primary care consultations was larger in females compared to males. There is evidence of a linear trend for primary care consultations and hospital admissions, while a trend also exists for hospital outpatient visits [33].

Van Ooström et al. [34] found that patients with multimorbidiy had significantly more face-to-face consultations, telephone consultations, home visits, diagnostics or minor surgery and contacts for prescribing medications in general practice than patients with one or no chronic disease. The number of chronic diseases was linearly associated with the number of contacts in general practice. The number of general practice contacts increased with the number patients with multimorbidity [34]. Patients with heart failure and comorbid diseases had the most contacts with general practice. The number of contacts per disease decreased with each extra disease. van Ooström et al. [34] demonstrated a significantly lower number of contacts in general practice for those with specific combinations of two chronic diseases than would be expected on the basis of the contact frequency associated with each individual chronic disease. The confidence interval indicated that the number of contacts per year was lower than expected on the basis of the number of yearly contacts for diabetes and for coronary heart disease separately. There were no disease pairs where the number of contacts was higher than expected on the basis of the contact frequency associated with the separate diseases [34].

\subsection{Higher Mortality}

Tooth et al. [26] developed and validated multimorbidity indexes to predict mortality, visits to general practitioners and specialists, hospitalization and Ability for daily living (ADL) in a population-based sample of older Australian women. Seven types of chronic condition such as cancer and stroke were significantly associated with the risk of mortality, different use of healthcare services and predicted a high frequency of contact with general practitioners [26]. Seven of the 19 explanatory variables were statistically 
significant in the stepwise proportional hazards regression analysis of mortality; these were heart disease, stroke, low iron, bronchitis/emphysema, diabetes, all forms of cancer other than skin and Alzheimer's disease [26]. Several chronic conditions were strongly associated with all health care service use outcomes. The presence of Alzheimer's disease was very strongly associated with the need for assistance. The regression coefficients from these models were used to produce the weights for each of the outcomes, after which the weights were employed to construct weighted scores [26]. Mortality had an essentially linear relationship with both the weighted and unweighted scores [26].

\section{Discussion}

The aim of this study was to illuminate the challenges faced by the healthcare services in managing the needs of older patients with multimorbidity. Six themes emerged; A frequent problem in older female patients; High healthcare expenditure and costs, Medication management problems, Social inequities, Complex healthcare and consultation needs and High mortality.

$A$ frequent problem in older female patients, The findings revealed that multimorbidity often increases with higher age and is more common in women. This was partly supported by Schäfer et al. [37] in relation to higher age. However, in the same study they suggested that there might be no gender differences in multimorbidity based on their findings that a larger number of patients with multimorbidity were male, which is in contrast to other studies in which multimorbidity was found to be more common in females and that female gender seems to be associated with multimorbidity [37] [38].

Some decades ago Feinstein [39] introduced the term multimorbidity and comorbidity (the previously used concept). Today, there seems to be little consensus on which chronic diseases and conditions should be considered and how exactly they should be assessed, summarized and weighted in order to arrive at some overall measure of burden. Many of the health complaints in old age are chronic and multiple conditions interact. There is an ongoing debate within health sciences on how to define these constructs and which instruments should be used to ensure standardized assessment of study results [40] [41]. A questionnaire to assess multimorbidity in primary care was developed and validated in an Indian study [42]. The authors demonstrated that the Multimorbidity Assessment Questionnaire for Primary Care (MAQ-PC) is a valid and reliable measure of multimorbidity in primary care practice [42].

High healthcare expenditure and costs was another finding in patients with multimorbidity. The number of chronic disorders/diseases in one person results in financial burden and pressure on the healthcare system. Many older patients have several diseases, which has a range of implications for how the healthcare system provides and assesses health care [9]. Findings from the USA show that multimorbidity accounts for up to $75 \%$ of all healthcare expenditure [43]. In Europe, multimorbidity is estimated to account for $70 \%-80 \%$ of healthcare expenditure in countries such as Denmark [43]. Older patients with chronic mental health conditions are a challenge because they are 
often unwilling to reach out for help from the health services. Sometimes general practitioners are not aware that in addition to other chronic diseases, older patients also suffer from anxiety and/or depression.

Medication management problems were found in patients with multimorbidity. The participants in the study by Summer Meranius and Engstrom [3] experienced uncertainty about side effects, leading to concern that the medication might be harmful [3]. The uncertainty seemed to be reinforced by a fear of medical error when several physicians were involved. This meant living with ambivalence when taking medication, which required a trade-off between symptom relief and reduced side effects. The healthcare system has a traditional view of the patient-doctor relationship, where the nurse is viewed as an assistant to the doctor [5]. Changing the roles of the healthcare professional and the patient to one that involves shared decision-making has been outlined in several studies [21]. Shared decision-making can enhance the care relationship as it involves a better balance of power between the patient and the healthcare professional [21].

Social inequities were revealed in this review, often related to low socio-economic status. Other studies that are not included in the present review have also demonstrated that socio-economic status has an impact on both prevalence rates and healthcare utilization rates [10] [43] [44]. Kuo and Lai [44] found that cases of patients with multimorbidity varied according to socio-economic status and demographic characteristics. In terms of socio-economic status, patients with multimorbidity included farmers, fishermen and others on low incomes. Demirchyan et al. [45] revealed that stressful life events and poor social support were among the psychosocial determinants of patients with multimorbidity. However, the mean age of those participants was 58.4 years and several were under 50 years old. The authors concluded that there were social inequities in their study population, indicating that inequities pose a serious threat to both individual and public health outcomes. Such social inequities could be reduced by a healthier lifestyle and by strengthening social networks in order to reduce the burden of multimorbidity. Older patients with several physical complaints and diseases in addition to depression have been described as experiencing stigma [16] because they perceived that physicians only focused on their depression and did not take their physical diseases and complaints seriously, which left them feeling neglected and uncertain, as reported in the study by Summer Meranius and Engstrom [3].

Complex healthcare and consultation needs were described as characteristic in several studies and can be a challenge for the healthcare services. Research has revealed that factors related to patients' experiences of healthcare and treatment impact on various types of self-management. Patient perceptions of multimorbidity do not seem to be a critical predictor of self-management, but can indicate how these patients view their health in the short term [49] and why healthcare becomes increasingly complex due to more specialist consultations. Self-management has been defined as "the care taken by individuals of their own health and well-being" and comprises the actions they take to lead a healthy lifestyle; to meet their social, emotional, psychological and physical needs; to care for their long-term condition; and to prevent further illness or accidents 
[50]. According to Kenning et al. [49], innovations and redesign of the healthcare system or the delivery system are necessary. Older patients require better support to cope with the emotional consequences of multimorbidity. Healthcare professionals need to change their traditional authoritative role to one that allows them to form partnerships with their patients within a shared decision-making perspective [21]. However, self-management does not always fulfil the aim of autonomy or empowerment. Redman [51] holds that self-management can lead to an unreasonable shift of responsibility.

High mortality was a characteristic described in this review. However, research on older patients with multimorbidity and mortality in the elderly has reported contradictory results [46]. Epidemiological studies that compared data from various European countries such as Finland, Italy and The Netherlands found that patients with multimorbidity were significantly associated with an increased risk of death [47]. This supports the results of Tooth et al. [26] in the present review. Do such patients suffer more than other older patients with a single disease or chronic condition? Landi et al. [46] examined the combined effect of multimorbidity and disability, where the effect of disability on the risk of death was higher than that of multimorbidity. The results showed that disability exerts an important influence on mortality, independent of age and other clinical and functional variables. Many studies demonstrate that anxiety and depression are common in patients with multimorbidity [47]. In other words, multimorbidity such as cardiovascular disease, diabetes, as well as pulmonary and neurological disorders, is common in patients who suffer from psychiatric disorders/conditions [48]. Patients with two or more chronic diseases, in addition to mental health conditions such as depression and anxiety, are at risk of high mortality because of the seriousness of their physical and mental health disorders.

\subsection{Limitations of the Included Studies}

Risk of bias will be discussed in this section, as suggested by Schneider et al. [24] and Polit and Beck [19]. Bias is defined as influence that produces a distortion of the results, thus threatening validity and trustworthiness [19].

The design of five studies was described as cross-sectional, one study took the form of a survey, while one study was part of a longitudinal design (Table 2). Cross-sectional studies, surveys and longitudinal studies can employ an observational design. Two studies contained scare information about the design [32] [34]. Observational designs can have limitations in their ability to determine "causality" ([24], p. 163), which was mentioned in one study [29]. The implications of studies with an observational design can be weakened by the fact that the participants may change over time, which Polit and Beck ([52], pp. 246-247) called the "history and/or maturity threat". A longitudinal design typically requires the participants to retrospectively summarize the extent to which they employed various strategies over a long period and is more likely to produce inaccurate results due to memory bias, compared to measurements that focus on a shorter timeframe. However, none of the included studies stated that the retrospective design could decrease validity and/or trustworthiness. A prospective design starts with a presumed cause and continues with a presumed effect [52]. It was stated in two studies 
that self-reported data were used [26] [30]. Tooth et al. [26] mentioned that the limitations of self-reported data must be acknowledged. Self-reports can increase the likelihood of response bias [25]. The two studies that employed self-reports described this method as a limitation that can decrease validity and lead to bias [26] [30]. There was no reference to methodology in any of the included studies.

Statistical power depends on sample and effect size, while non-significant implications must be interpreted with caution [24] [25]. Failure to show significance was described as due to lack of power. However, this information was not related to methodological literature. Two studies described having a relatively small sample size (Table 2), but did not mention selection bias as a limitation. The use of only one group was not referred to as decreasing validity in these two studies. In the opinion of the authors of this review (ALH, AB, ES), the lack of common measurements and definitions of the concept of multimorbidity is the most serious limitation.

\subsection{Limitation of this Review}

A limitation of this review is the fact that one of the studies comes from Switzerland, one from Ireland, one from Germany, one from The Netherlands (four from Europe), one from USA, one from Canada and one from Brazil (three from south and north America), and two from Australia (see Table 2). The different cultures in these parts of the world must be taken into consideration; for example, the various countries seem to have different way of registering and defining multimorbidity in clinical settings. Further studies are required, as is the development of measures and common strategies for deciding which chronic diseases and conditions should be included in samples. Researchers need to strengthen the design, validity and reliability of quantitative studies on multimorbidity.

\section{Conclusion}

Patients should have their chronic diseases reviewed by a clinician with responsibility for coordinating their care. The fragmentation of the healthcare system must be stopped and steps be taken to ensure that each patient has a so-called healthcare plan. In order to reduce the burden of several chronic diseases, healthcare professionals need to focus more on the patients' experiences, physical and mental health, as well as their social functioning. To ensure safe and effective care for elderly persons with multimorbidity, healthcare services should move away from the current focus on managing innumerable individual diseases.

\section{Implications for Clinical Practice}

Healthcare services need innovation, including a redesign of care, patient-centred integration across settings and coordination of primary care [53]. Today, there seems to be little focus on patient safety and preventing harm when caring for a patient with multimorbidity. According to Tinetti et al. [53], none of the healthcare services address necessary aspects of healthcare such as decision making across conditions appropriate for 
patients with multimorbidity. Healthcare professionals seem to struggle to obtain suitable guidelines pertaining to caring for patients with multimorbidity while responding to patient needs [54] [55]. To promote adequate healthcare for older people with multimorbidity, innovative ways must be found to integrate and coordinate the care across conditions and between different healthcare professional categories. Such a healthcare model should be person-focused instead of disease focused [53]. Person-centred healthcare might be an alternative form of care and treatment to promote shared decision making [56]. Today, various healthcare providers do not address the treatment burden and potential harm involved in caring for a patient with several diseases [53]. To promote adequate healthcare for older people with multimorbidity, innovative strategies must include a plan of how to coordinate the healthcare system. Consulting a different specialist for each chronic disease is confusing [57]. There is an urgent need for a coordinator with expertise and experience in caring for older patients with multimorbidity to supervise the provision of care within the context of each patient's health goals and priorities. Older people with multimorbidity require coordinated input from an interdisciplinary or a multidisciplinary healthcare team that is able to meet each patient's needs [58].

\section{Acknowledgements}

We want to thank Monique Federsel for reviewing the English language.

\section{References}

[1] Banerjee, S. (2015) Multimorbidity-Older Adults Need Health Care That Can Count Past One. The Lancet, 385, 587-589. http://dx.doi.org/10.1016/S0140-6736(14)61596-8

[2] Koller, D., Schon, G., Schafer, I., Glaeske, G., van den Bussche, H. and Hansen, H. (2014) Multimorbidity and Long-Term Care Dependency-A Five-Year Follow-Up. BMC Geriatrics, 14, 70. http://dx.doi.org/10.1186/1471-2318-14-70

[3] Summer Meranius, S. and Engstrom, G. (2015) Experience of Self-Management of Medications among Older People with Multimorbidity. Journal of Clinical Nursing, 24, 2757-2764. http://dx.doi.org/10.1111/jocn.12868

[4] Bayliss, E.A., Edwards, A.E., Steiner, J.F. and Main, D.S. (2008) Processes of Care Desired by Elderly Patients with Multimorbidities. Family Practice, 25, 287-293. http://dx.doi.org/10.1093/fampra/cmn040

[5] Fortin, M., Hudson, C., Gallagher, F., Ntetu, A.L., Maltais, D. and Soubhi, H. (2010) Nurses Joining Family Doctors in Primary Care Practices: Perceptions of Patients with Multimorbidity. BMC Family Practice, 11, 84. http://dx.doi.org/10.1186/1471-2296-11-84

[6] Grundberg, A., Ebbeskog, B., Dahlgren, M.A. and Religa, D. (2012) How CommunityDwelling Seniors with Multimorbidity Conceive the Concept of Mental Health and Factors That May Influence It: A Phenomenographic Study. International Journal of Qualitative Studies on Health and Well-Being, 7, 19716. http://dx.doi.org/10.3402/qhw.v7i0.19716

[7] Gustafsson, M., Kristensson, J., Hols, G., Willman, A. and Bohman, D. (2013) Case Managers for Older Persons with Multi-Morbidity and Their Everyday Work-A Focused Ethnography. BMC Health Services Research, 13, 496.

http://www.biomedcentral.com/1472-6963/13/496

http://dx.doi.org/10.1186/1472-6963-13-496 
[8] Noël, P.H., Parchman, M., Williams Jr., J.W., Cornell. J.E., Shuko, L., Zeber, J.E., Kazis, L.E., Lee, A.F.S. and Puch, J.A. (2007) The Challenges of Multimorbidity from the Patient Perspective. Journal of General Medicine, 22, 419-424. http://dx.doi.org/10.1007/s11606-007-0308-Z

[9] Salisbury, C. (2012) Multimorbidity: Redesigning Health Care for People Who Use It. The Lancet, 380, 7-9. http://dx.doi.org/10.1016/S0140-6736(12)60482-6

[10] Barnett, K., Mercer, S.W., Norbury, M., Watt, G., Wyke, S. and Guthrie, B. (2012) Epidemiology of Multimorbidity and Implications for Health Care, Research, and Medical Education: A Cross-Sectional Study. The Lancet, 380, 37-43. http://dx.doi.org/10.1016/S0140-6736(12)60240-2

[11] Boyd, C.M. and Fortin, M. (2010) Future of Multimorbidity Research: How Should Understanding of Multimorbidity Inform Health System Design? Public Health Reviews, 32, 451474.

http://search.proquest.com/openview/638d283bbbbd682359b8479823765fbc/1?pq-origsite= gscholar

[12] Valderas, J.M., Starfield, B., Sibbald, B., Salisbury, C. and Roland, M. (2009) Defining Comorbidity: Implications for Understanding Health and Health Services. Annals of Family Medicine, 7, 357-363. http://dx.doi.org/10.1370/afm.983

[13] Starfield, B. (2006) Threads and Yarns: Weaving the Tapestry of Comorbidity. Annals of Family Medicine, 4, 101-103. http://dx.doi.org/10.1370/afm.524

[14] Yeung, A., Feldman, G. and Fava, F. (2010) Self-Management of Depression: A Manual for Mental Health and Primary Care Professionals. Cambridge University Press, Cambridge.

[15] Holm, A.L., Lyberg, A., Lassenius, E., Berggren, I. and Severinsson, E. (2013) Older Persons' Lived Experiences of Depression and Self-Management. Issues in Mental Health Nursing, 34, 757-764. http://dx.doi.org/10.3109/01612840.2013.809829

[16] Holm, A.L., Lyberg, A. and Severinsson, E. (2014) Living with Stigma: Depressed Elderly Persons' Experiences of Physical Health Problems. Nursing Research and Practice, 2014, Article ID: 527920. http://dx.doi.org/10.1155/2014/527920

[17] Holm, A.L., Lyberg, A., Aström, I. and Severinsson, E. (2014) Social Capital and Depressive Ill-Health-An Evaluative Approach to the Implementation of the Chronic Care Model (CCM). Open Journal of Nursing, 4, 683-694. http://www.scirp.org/journal/ojn http://dx.doi.org/10.4236/ojn.2014.410073

[18] Gress, S., Baan, C.A., Clanan, M., Dedeu, T., Groenewegen, P., Howson, H., Maroy, L., Nolte, E., Redaélli, M., Saarelma, O., Schmacke, N., Schumacher, K., van Lente, E.J. and Vrijhoef, B. (2009) Co-Ordination and Management of Chronic Conditions in Europe: The Role of Primary Care. Position Paper of the European Forum for Primary Care. Quality of Primary Care, 17, 75-86.

[19] Polit, D.F. and Beck, C.T. (2012) Nursing Research: Generating and Assessing Evidence for Nursing Practice. Wolters Kluwer Health/Lippincott Williams \& Wilkins, Philadelphia.

[20] Holm, A.L. and Severinsson, I.E. (2016) Intuition-A Way of Knowing in Clinical Nursing? A Systematic Review. Open Journal of Nursing, 6, 412-425. http://dx.doi.org/10.4236/ojn.2016.65043

[21] Holm, A.L., Berland, A. and Severinsson, I.E. (2016) Older Patients' Involvement in Shared Decision-Making-A Systematic Review. Open Journal of Nursing, 6, 170-185. http://dx.doi.org/10.4236/ojn.2016.63018

[22] Liberati, A., Altman, D.G., Tetzlaff, J., Mulrow, C., Götzsche, P., Ionnidis, J.P., Clarke, M., Devereaux, P.J., Kleijnen, D. and Moher, D. (2009) The PRISMA Statement for Reporting 
Systematic Reviews and Meta-Analyses of Studies That Evaluate Healthcare Interventions: Explanation and Elaboration. BMJ, 339, b2700.

http://www.prisma-statement.org/2.1.1\%20-\%20PRISMA\%202009\%20Checklist.pdf http://dx.doi.org/10.1136/bmj.b2700

[23] Jesson, J., Matheson, L. and Lacey, F. (2011) Doing Your Literature Review: Traditional and Systematic Techniques. SAGE, London.

[24] Schneider, Z., Whitehead, E., Elliott, D., Lobiondo-Wood, G. and Haber, J. (2007) Nursing \& Midwifery Research Methods and Appraisal for Evidence-Based Practice. Elsevier, New York.

[25] Shadish, W.R., Cook, T.D. and Campbell, D.T. (2002) Experimental and Quasi-Experimental Designs for Generalized Causal Reference. Houghton Miffin, Boston.

[26] Tooth, L., Hockey, R., Byles, J. and Dobson, A. (2008) Weighted Multimorbidity Indexes Predicted Mortality, Health Service Use, and Health-Related Quality of Life in Older Women. Journal of Clinical Epidemiology, 61, 151-159. http://dx.doi.org/10.1016/j.jclinepi.2007.05.015

[27] Jowsey, T., McRae, I.S., Valderas, J.M., Dugdale, P., Phillips, R., Bunton, R., Gillespie, J., Banfield, M., Jones, L., Kljakovic, M. and Yen, L. (2013) Time's Up. Descriptive Epidemiology of Multi-Morbidity and Time-Spent on Health Related Activity by Older Australians: A Time Use Survey. PLoS ONE, 8, e59379. http://dx.doi.org/10.1371/journal.pone.0059379

[28] Orueta, J.F., Garcia-Alvare, A., Garcia-Goni, M., Paolucci, F. and Nuno-Solinis, R. (2014) A Population Based Study Using Health Administrative Databases. PLoS ONE, 9, e89787. http://dx.doi.org/10.1371/journal.pone.0089787

[29] Bähler, C., Huber, C.A., Brüngger, B. and Reich, O. (2015) Multimorbidity, Health Care Utilization and Costs in an Elderly Community-Dwelling Population: A Claims Data Based Observational Study. BMC Health Services Research, 15, 23. http://dx.doi.org/10.1186/s12913-015-0698-2

[30] Nunes, B.P., Thume, E. and Facchini, L.A. (2015) Multimorbidity in Older Adults: Magnitude and Challenges for the Brazilian Health System. BMC Public Health, 15, 1172-1183. http://dx.doi.org/10.1186/s12889-015-2505-8

[31] Perruccio, A.V., Katz, J.N. and Losina, E. (2012) Health Burden in Chronic Disease: Multimorbidity Is Associated with Self-Rated Health More than Medical Comorbidity Alone. Journal of Clinical Epidemiology, 65, 100-106.

http://dx.doi.org/10.1016/j.jclinepi.2011.04.013

[32] Holzhausen, M., Fuchs, J., Busch, M., Ernert, A., Six-Merker, J., Knopf, H., Hapke, U., Gaertner, B., Kurzawe-Seitz, I., Dietzel, R., Schödel, N., Welke, J., Wiskott, J., Wetzstein, M., Martus, P. and Scheidt-Nave, C. (2011) Operationalizing Multimorbidity and Autonomy for Health Services Research in Aging Populations-The OMAHA Study. BMC Health Services Research, 11, 47. http://dx.doi.org/10.1186/1472-6963-11-47

[33] Glynn, L.G., Valderas, J.M., Healy, P., Bruke, E., Newell, J., Gillespie, P. and Murphy, A.W. (2011) The Prevalence of Multimorbidity in Primary Care and Its Effect on Health Care Utilization and Cost. Family Practice, 28, 516-523. http://dx.doi.org/10.1093/fampra/cmr013

[34] Van Oostrom, S.H., Picavet, H.S., de Bruin, S.R., Stirbu, I., Schellevis, F.G. and Baan C.A. (2013) Multimorbidity of Chronic Diseases and Health Care Utilization in General Practice. BMC Family Practice, 15, 61. http://dx.doi.org/10.1186/1471-2296-15-61

[35] Pope, C., Mays, N. and Opay, J. (2007) Synthesizing Qualitative and Quantitative Health Evidence: A Guide to Methods. McGraw-Hill Open University Press, Maidenhead. 
[36] Holopainen, A., Hakulinen-Viitanen, T. and Tosavaine, K. (2008) Systematic Review-A Method for Nursing Research. Nurse Researcher, 6, 72-83.

http://dx.doi.org/10.7748/nr2008.10.16.1.72.c6754

[37] Schäfer, I., Hansen, H., Schön, G., Höfels, S., Altiner, A., Dahlhaus, A., Gensichen, J., Riedel-Heller, S., Weyerer, S., Blank, W.A., König, H.-H., von den Knesebeck, H., Scherer, M., van den Bussche, H. and Wiese, B. (2012) The Influence of Age, Gender and Socio-Economic Status on Multimorbidity Patterns in Primary Care. First Results from the Multicare Cohort Study. BMC Health Services Research, 12, 89.

http://www.biomedcentral.com/1472-6963/12/89 http://dx.doi.org/10.1186/1472-6963-12-89

[38] Salisbury, C., Johnson, L., Purdy, S., Valderas, J.M. and Mongomery, A.A. (2011) Epidemiology and Impact of Multimorbidity in Primary Care: A Retrospective Cohort Study. British Journal of General Practice, 61, 12-21. http://dx.doi.org/10.3399/bjgp11X548929

[39] Feinstein, A.R. (1970) The Pre-Therapeutic Classification of Co-Morbidity in Chronic Disease. Journal of Chronic Diseases, 23, 455-468. http://dx.doi.org/10.1016/0021-9681(70)90054-8

[40] Haywood, K.L., Garratt, A.M. and Fitzpatrick, R. (2005) Quality of Life in Older People: A Structured Review of Generic Self-Assessed Health Instruments. Quality of Life Research, 14, 1651-1668. http://dx.doi.org/10.1007/s11136-005-1743-0

[41] Moons, P., Budts, W. and De Geest, S. (2006) Critique on the Conceptualisation of Quality of Life: A Review and Evaluation of Different Conceptual Approaches. International Journal of Nursing Studies, 43, 891-901. http://dx.doi.org/10.1016/j.ijnurstu.2006.03.015

[42] Pati, S., Akhtar Hussain, M., Svain, S., Salisbury, C., Metsemakers, J.F.M., Knottnerus, J.A. and van den Akker, M. (2016) Development and Validation of a Questionnaire to Assess Multimorbidity in Primary Care: An Indian Experience. BioMed Research International, 2016, Article ID: 6582487. http://dx.doi.org/10.1155/2016/6582487

[43] World Health Organization (WHO) (2006) Tackling Europe's Major Diseases: The Challenges and the Solutions. World Health Organization, Copenhagen.

[44] Kuo, R.N. and Lai, M-S. (2013) The Influence of Socio-Economic Status and Multimorbidity Patterns on Healthcare Costs: A Six-Year Follow-Up Under a Universal Healthcare System. International Journal of Equity in Health, 12, 69.

http://www.equityhealthj.com/content/12/1/69

http://dx.doi.org/10.1186/1475-9276-12-69

[45] Demirchyan, A., Khachadourian, V., Armenian, H.K. and Petrosyan, V. (2013) Short and Long Term Determinants of Incident Multimorbidity in a Cohort of 1988 Earthquake Survivors in Armenia. International Journal for Equity in Health, 12, 68.

http://www.equityhealthj.com/content/12/1/68

http://dx.doi.org/10.1186/1475-9276-12-68

[46] Landi, F., Liperoti, R., Russo, A., Capoluongo, E., Barillaro, C., Pahor, M., Bernabei, R. and Onder, G. (2010) Disability, more than Multimorbidity, was Predictive of Mortality among Older Persons Aged 80 Years and Older. Journal of Clinical Epidemiology, 63, 752-759. http://dx.doi.org/10.1016/j.jclinepi.2009.09.007

[47] Van den Brink, A.M., Gerritsen, D.L., Voshaar, R.C. and Koopman, R.T. (2013) Residents with Mental-Physical Multimorbidity Living in Long-Term Care Facilities: Prevalence and Characteristics. A Systematic Review. International Psychogeriatrics, 25, 531-548. http://dx.doi.org/10.1017/S1041610212002025

[48] Lyketsos, C.G., Dunn, G., Kaminsky, M.J. and Breakey, W.R. (2002) Medical Comorbidity in Psychiatric Inpatients: Relation to Clinical Outcomes and Hospital Length of Stay. Psychosomatics, 43, 24-30. http://dx.doi.org/10.1176/appi.psy.43.1.24 
[49] Kenning, C., Coventry, P.A., Gibbons, C., Bee, P., Fisher, L. and Bower, P. (2015) Does Patient Experience of Multimorbidity Predict Self-Management and Health Outcomes in a Prospective Study in Primary Care? Family Practice, 32, 311-316.

http://dx.doi.org/10.1093/fampra/cmv002

[50] Department of Health (2006) Our Health, Our Care, Our Say: A New Direction for Community Services. The Stationary Office, London.

[51] Redman, B.K. (2005) The Ethics of Self-Management Preparation for Chronic Illness. Nursing Ethics, 12, 361-369. http://dx.doi.org/10.1191/0969733005ne801oa

[52] Polit, D.F. and Beck, C.T. (2006) Essentials of Nursing Research: Methods, Appraisal, and Utilization. Lippincott Williams \& Wilkins, Philadelphia.

[53] Tinetti, M.E., Fried, T.R. and Boyd, C.M. (2012) Designing Health Care for the Most Common Chronic Condition-Multimorbidity. JAMA, 307, 2493-2494.

http://dx.doi.org/10.1001/jama.2012.5265

[54] Bower, P., Macdonald, W., Harkness, E., Gask, L., Kendrick, T., Valderas, J.M., Dickens, C., Blakeman, T. and Sibbald, B. (2011) Multimorbidity, Service Organization and Clinical Decision Making in Primary Care: A Qualitative Study. Family Practice, 28, 579-587. http://dx.doi.org/10.1093/fampra/cmr018

[55] Fried, T.R., Tinetti, M.E. and Iannone, I. (2011) Primary Care Clinicians' Experiences with Treatment Decision Making for Older Persons with Multiple Conditions. Archives of Internal Medicine, 171, 75-80. http://dx.doi.org/10.1001/archinternmed.2011.424

[56] Boyd, C.M., Boult, C., Shadmi, E., Leff, B., Brager, R., Dunbar, L., Wolff, J.L. and Wegener, S. (2007) Guided Care for Multimorbid Older Adults. The Gerontologist, 47, 697-704. http://dx.doi.org/10.1093/geront/47.5.697

[57] Burgers, J.S., Voerman, G.E., Grol, R., Faber, M.J. and Schneider, E.C. (2010) Quality and Coordination of Care for Patients with Multiple Conditions: Results from an International Survey of Patient Experience. Evaluation of Health Professionals, 33, 343-364. http://dx.doi.org/10.1177/0163278710375695

[58] Holm, A.L. and Severinsson, E. (2014) Perceptions of the Need for Improvements in Healthcare after Implementation of the Chronic Care Model. Nursing and Health Sciences, 16, 442-228. http://dx.doi.org/10.1111/nhs.12136

\section{Submit or recommend next manuscript to SCIRP and we will provide best service for you:}

Accepting pre-submission inquiries through Email, Facebook, LinkedIn, Twitter, etc.

A wide selection of journals (inclusive of 9 subjects, more than 200 journals)

Providing 24-hour high-quality service

User-friendly online submission system

Fair and swift peer-review system

Efficient typesetting and proofreading procedure

Display of the result of downloads and visits, as well as the number of cited articles

Maximum dissemination of your research work

Submit your manuscript at: http://papersubmission.scirp.org/

Or contact ojn@scirp.org 